\title{
COMPUTER GUIDED FLAPLESS VESTIBULAR TO LINGUAL TRANS- ALVEOLAR IMPLANT INSERTION FOR ALL ON FOUR IMPLANT PROSTHESIS IN CASE OF SEVERELY ATROPHIED MANDIBLE: A SHORT TERM CLINICAL AND RADIOGRAPHIC STUDY
}

\author{
Samah I Mourad*, Sally Awad* and Ali Shamaa**
}

\begin{abstract}
Aim: This short-term investigation aimed to study the outcomes of computer guided flapless vestibular to lingual implant insertion for All on four implant prosthesis in case of severely atrophied mandible.

Material and methods: Six ( 3 men and 3 women) edentulous patients (mean age of 59 years) with atrophied mandibles received four implants using the computer guided flapless surgical protocol and a stereolithographic surgical guide. The posterior implant was installed in bicuspid region lingual to mental foramen and inclined in buccolingual trans-alveolar direction to engage the lingual cortical plate. Fixtures were loaded by the old denture the same day of implant placement. Plaque and bleeding scores, probing depth, fixture mobility and loss of bone around implants were measured at baseline (immediately after loading), 6 and 12 months thereafter.
\end{abstract}

Results: There was a significant increase in plaque scores, probing depth and resorption of bone with passage of time. gingival scores and stability of the implants did not change with time. Premolar implants showed significant higher plaque scores, probing depth and marginal loss of bone compared to canine implants. Two posterior implants were lost resulting in survival rate of $91.6 \%$ after one year.

Conclusion: Within the limits of this study, it could be concluded that computer guided flapless vestibular to lingual trans-alveolar posterior implant insertion for All on four implant prosthesis in case of severely atrophied mandible is a predictable and reliable method as it was associated with favourable clinical and radiographic peri-implant outcomes after one year.

KEY WORDS: Computer guided, flapless, implants, severely atrophied, mandible.

* Associate Professor, Department of Oral and Maxillofacial Surgery, Faculty of Dentistry, Mansoura University, Mansoura, Egypt.

** Professor, Department of Oral Biology, Faculty of Dentistry, Minia University, Egypt. 


\section{INTRODUCTION}

The restoration of extremely atrophied mandibular jaw using implant-fixed prosthesis is usually difficult due to poor quality and amount of remaining bone. Most patients wearing complete dentures had problem related to stability of their dentures, with difficulty in mastication, and require a fixed prosthetic solution. ${ }^{(1)}$. Completely edentulous mandible can be managed by several implant treatment options, such as implant overdentures, fixed porcelain fused to metal implant supported prostheses, or fixed implant supported hybrid prosthesis ${ }^{(2)}$.

With All-on-Four implant treatment, bone augmentation and inferior alveolar nerve displacement are omitted. The concept involve strategic implant positioning to enhance prosthetic support (i.e., two implants inserted vertically in the or canine regions and two distally tilted implants $\left(30^{\circ}\right)$ just mesial to the mental foramen) ${ }^{(3,4)}$. This approach provides long posterior implants, improves the bone/implant anchorage. Furthermore, restoration support is improved due to increasing the antroposteriror spread and shortening of cantilevers which provide optimum load sharing. Additionally, the grafting procedures may be omitted, causing reduced morbidity and costs. Moreover, the immediate function concept represents a major advantage for patients, providing less time-consuming treatments ${ }^{(5,6)}$. Most definitive prostheses included 12 teeth thanks to good locations obtained by distal tilting of the posterior fixtures ${ }^{(7)}$

The severely atrophic mandible, (Cawood Class IV-V) ${ }^{(8)}$, can still be managed with dental implants without bone grafting using immediate loading in a modified "All on-four" concept. In the all-on-4 technique, tilting the posterior implant increases the length in the bone by $50 \%{ }^{(9)}$.

When there is a $10 \mathrm{~mm}$ of bone available above the anterior border of the mental loop, this allows a $10 \mathrm{~mm}$ distalization of the posterior implants when they inserted at $30^{\circ}$ distal inclination ${ }^{(10)}$. In case of sever alveolar bone resorption associated with mandibular atrophy and forward positioning of the mental nerve in the mandibular jaw, the implants can be placed trans-alveolarly, buccal to lingual to avoid mandibular nerve repositioning. When the posterior implants inclined $30^{\circ}$ distally from vertical plane it will engage the lingual plate and provide adequate antro-posterior spread and wide prosthetic base that allow favorable biomechanical load distribution. The implant located distal to the foramen to emerge in first or second premolar areas. These implants positioned vestibular to lingual over the nerve to engage lingual cortical plate and do not need abundant bone above the nerve. ${ }^{(9-11)}$

The computer guided flapless approach for All on four implant insertion provide several advantages including accuracy, precise transfer of the virtual planning 3-D model to the surgical template, precise detection and visualization of vital anatomical structures in relation to implant position, and attachment of the prosthesis immediately after abutment connection. Moreover, it simplifies treatment for patient and clinician, due to flapless surgical protocol, reduced operating time, and reduced inflammation and pain after surgery, with minimal complications ${ }^{(12)}$.

Reviewing the literature, the All-on-four implant prosthesis proved to be a successful treatment option for edentulous patients ${ }^{(13)}$. However, evaluation of the implants of this concept in severely compromised ridge is limited to case reports ${ }^{(9)}$. Furthermore, the use of vestibular to lingual trans-alveolar fixture insertion for atrophied jaws with anterior placement of the mental foramen still scarce and limited to open flap surgery. ${ }^{(1)}$ Accordingly, the aim of this short-term investigation was to study the outcomes of computer guided flapless vestibular to lingual implant insertion for All on four implant prosthesis in case of severely atrophied mandible. 


\section{MATERIALS AND METHODS}

\section{Patient cohort}

This study was conducted at Oral Surgery Department, Faculty of Dentistry, Mansoura University on six (3 men and 3 women) edentulous patients (mean age of 59 years) with the following inclusion criteria: 1) All patients complained from mandibular ridge atrophy with inadequate stabilization of their mandibular dentures, 2) Patients presented need for a fixed implant-restoration, 3) Good bone amount (class IV-VI Cawood and Howell ${ }^{(8)}$ and density in the interforaminal area of the mandible, and 4) buccal anatomical location of mental foramen and mental loop with sufficient bone lingual to the foramen to receive implants of at least $3.7 \mathrm{~mm}$ in diameter as verified by perioperative cone beam computerized tomography. Exclusion criteria include: 1) General contraindications for surgical procedures such as patients with head and neck radiotherapy, patients with bleeding disorders, hepatic patients, 2) Patients with diseases that jeopardize implant healing such as diabetes mellitus, and osteoporosis, 3) Long term immunosuppressive and corticosteroid drug therapy and smoking patient. All patients signed informed consents and the study plan was approved by the ethical committee.

\section{Surgical procedures}

Radiopaque gutta perchae markers are added to the polished surface of the mandibular denture at labial, buccal and lingual flanges. Dual scan protocol was followed using cone beam CT (CBCT, i-CAT, Imaging Sciences International ISI, Pennsylvania, USA), Firstly, the patients were scanned while wearing their mandibular dentures, then the mandibular dentures were scanned alone. The two data sets of the double scans were overlapped then opened with 3-D image treatment designing software (OnDemand). According to the CT scan, the implants were virtually planned according to the All On four protocol, then an individualized stereolithographic surgical guide was constructed using prototyping technique. The four implants were placed virtually in the optimizing position, angulation and distribution. Anterior fixtures were placed at cuspid/ lateral incisor position and posterior fixtures were planned in bicuspid area lingual to the foramen with safety margin from the foramina and the loop. The posterior implants were tilted distally to form a 30-degree angle from the vertical plane, then tilted in buccolingual transalveolar direction to engage the lingual cortical plate and emerged in the region of the second premolar or mesial cusp of first molar tooth (fig 1) ${ }^{(3,14)}$. Virtual model planning software was used to define the sites for implant placement and anchor pins for the surgical guide. A tissue born stereolithographic guide (fig 2) with 4 metal rings placed above the implant positions was fabricated using 3D printing process (In2Guide).

All participants administered diazepam before operation. Antibiotics (amoxicillin $625 \mathrm{mg}+$ clavulanic acid $125 \mathrm{mg}$, Augmentin ${ }^{\circledR} 1 \mathrm{gm}$ ) were prescribed before surgery and continued 6 days later. Corticosteroids (Dexamethazone ${ }^{\circledR}$ ) was given. Anti-inflammatory medication (ibuprofen ${ }^{\circledR}, 600$ mg) was administered for 4 days postoperatively. Analgesics (Ketolac ${ }^{\circledR} 10 \mathrm{mg}$ ) were given for 6 days. Local anesthesia was administered. Four implants (TioLogic, Dentaurum, Germany) were inserted according the flapless surgical protocol using the surgical guide and the universal surgical kit (In2Guide, Universal Kit Cybermed Inc) compatible with the tissue born template to be utilized during osteotomy preparation (fig 3). This kit includes hand drill sleeves with successive increasing diameters that fit the template sleeves. The hand sleeves were used during consecutive drilling procedures with surgical guide to accommodate successive increasing in drill diameter. The template was stabilized in the patient's mouth by a rubber base interocclusal record and attached to the mandibular bone by fixation pins. The minimum torque at implant placement was $35 \mathrm{Ncm}$ to permit immediate loading of the implants ${ }^{(15)}$. 


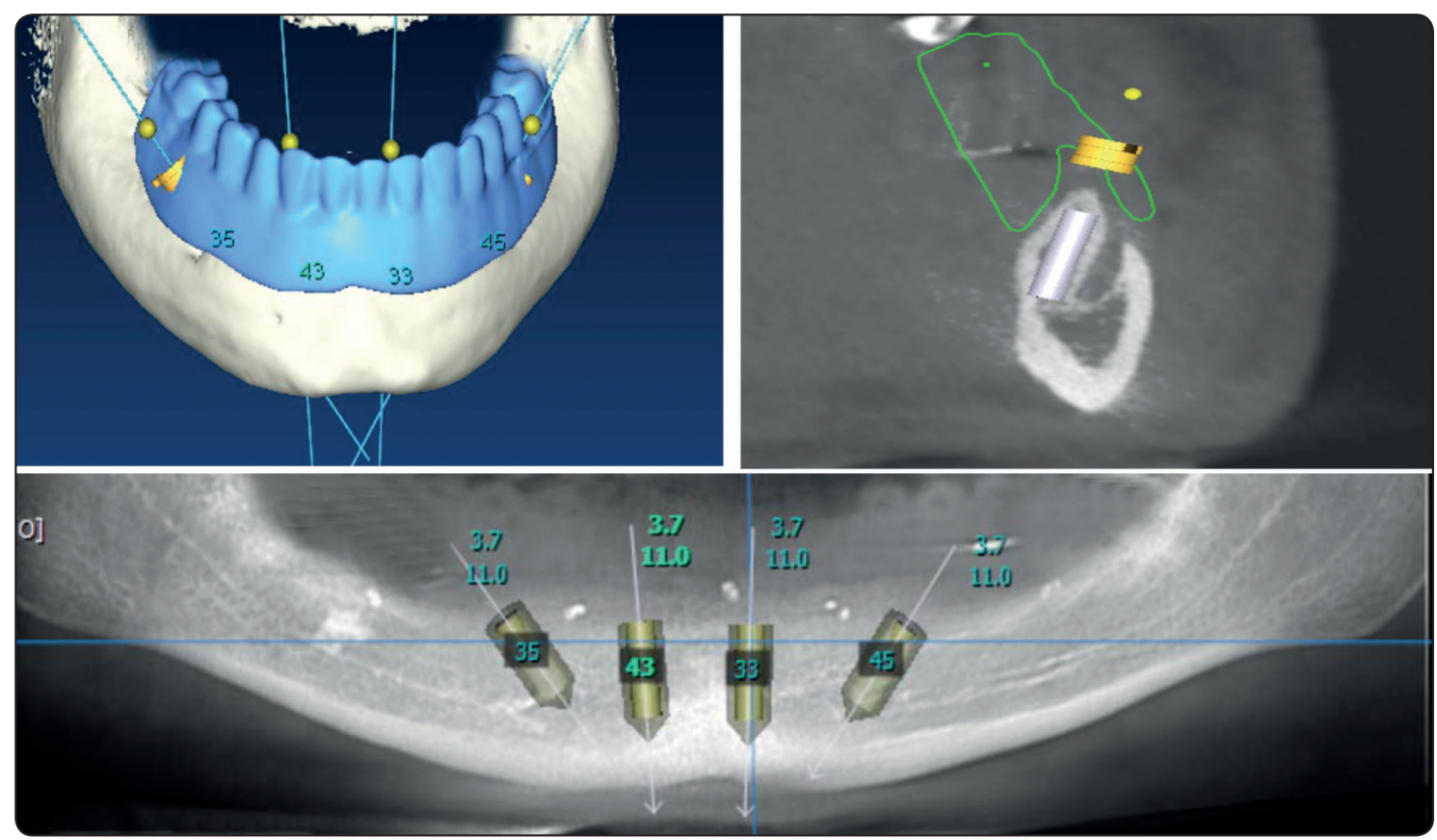

Fig. (1) Planning of implant position and orientation using Cone beam CT

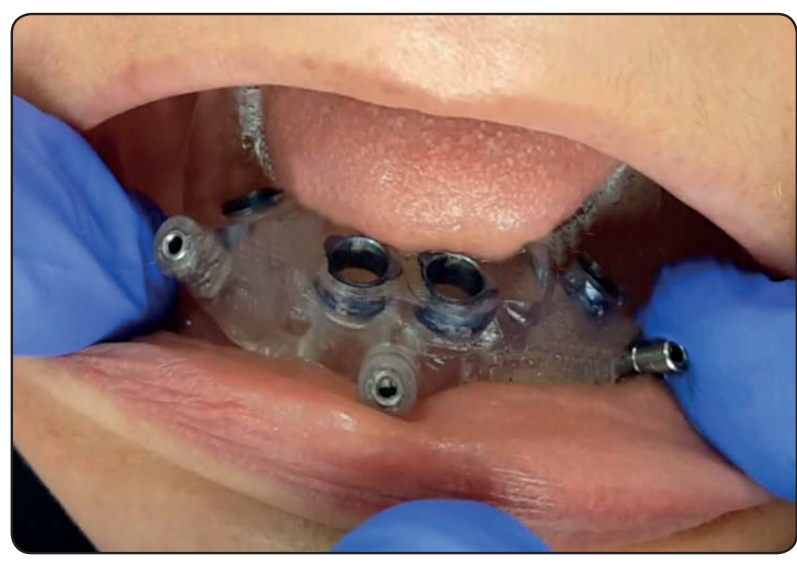

Fig. (2) Mucosal supported surgical guide

Straight multiunit abutments were threaded to the anterior fixtures and $30^{\circ}$ angled abutments were threaded to premolar fixtures at $20 \mathrm{Ncm}$ torque. Mulitunit abutments were oriented distal and buccal inclination of the implants. The 4 fixtures were loaded by the old denture on the same day of surgery. The denture was modified by removal of the labial and buccal flanges and the second molar ${ }^{(16)}$. Titanium caps were threaded to the abutments. The denture base opposite to the multiunit abutments was hollowed. The temporary metal caps were attached

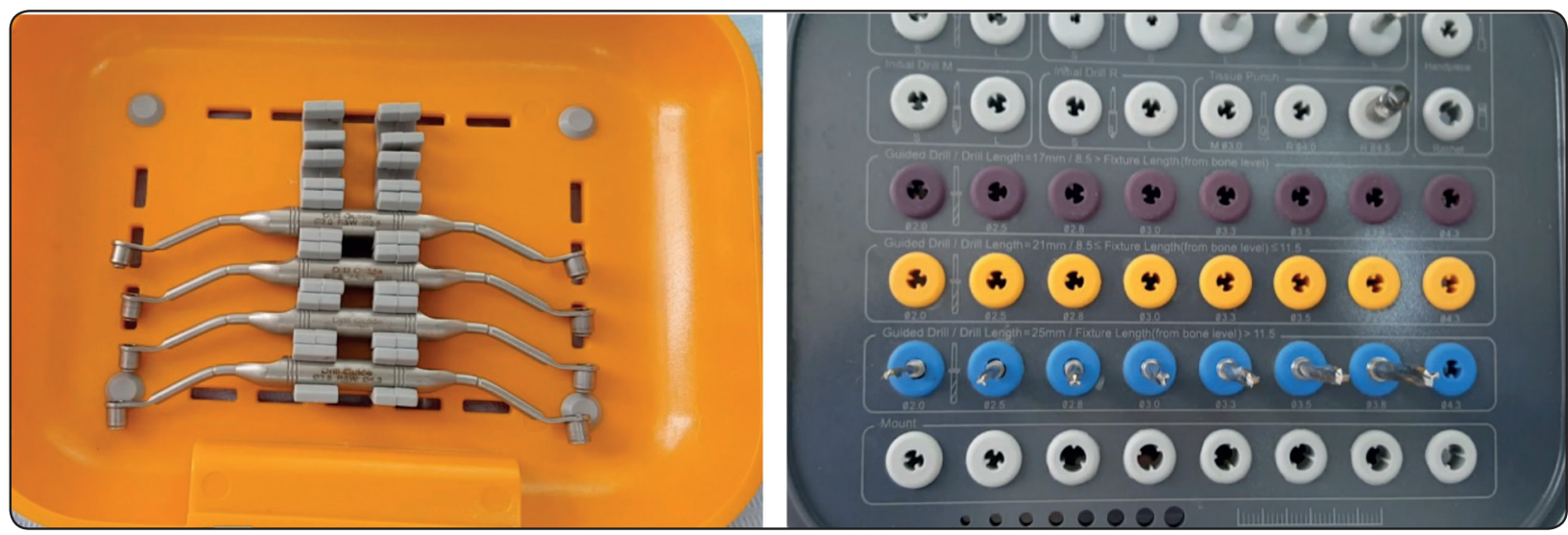

Fig. (3) In2Guide universal surgical kit 


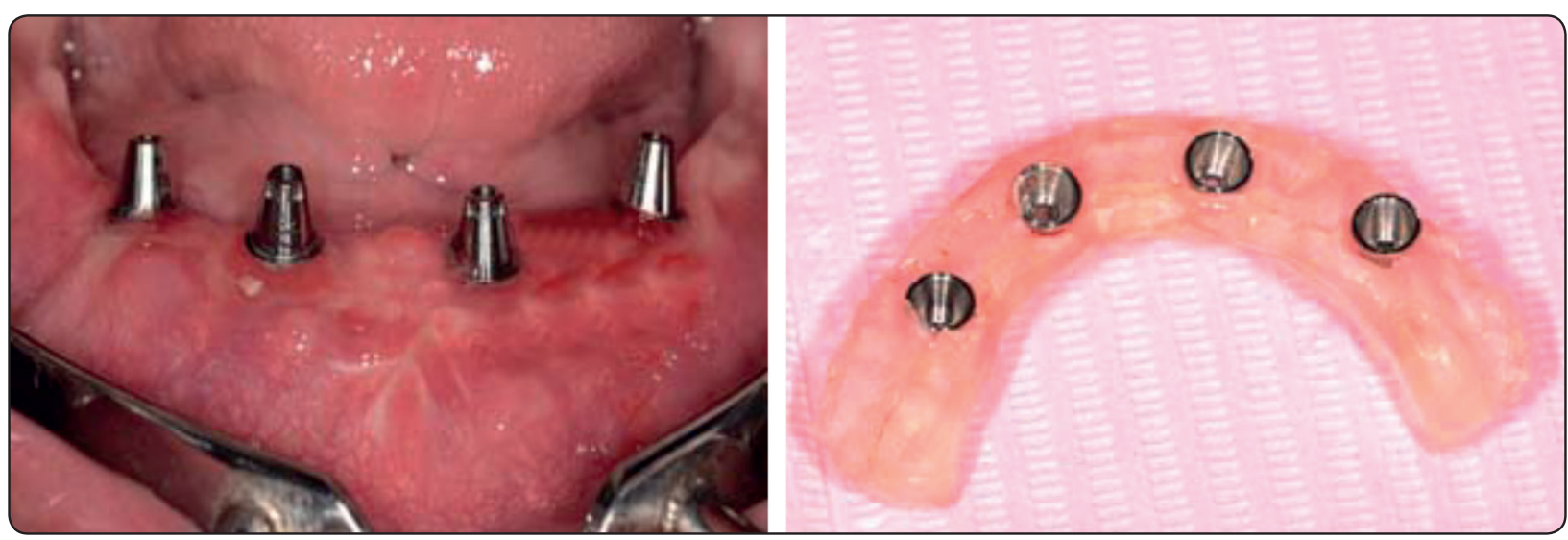

Fig. (4) Immediate loading of implants by mandibular dentures

to the denture using self-cure acrylic material (fig 4). The upper and lower first molar teeth were relieved to eliminate load on the angled premolar implants. Post-operative medications include analgesics, antibiotics, mouth rinse for 2 weeks and anti-inflammatory medication for 7 days. Soft diet was prescribed for all patients they told to and avoid hard foods. Participants were informed about oral hygiene instructions and reminded for follow-up visits to make modifications of the relined dentures till osseointegration occurs.

After 3 months of osseointegration period, open tray abutment level impression procedure was started. A stock/special tray was perforated over the transfer coping to allow unscrewing of the transfer after impression making. Light body rubber base impression (Zhermack®, Badia Polesine, Rovigo, Italy) was loaded around the impression posts. The tray was filled with putty impression material and seated so that the tips of all the guide pins are identified. The long transfer copings were unthreaded and the impression was removed from patient mouth. Abutment analogues were screwed to the transfer coping and the impression was poured to obtain master cast. Plastic caps were threaded to abutments on the master cast. The final prothesis was consisted of hybrid screw retained cobalt chromium (Co-Cr) framework covered by acrylic resin teeth and pink acrylic resin that replace lost bone and gingival tissues was used as the final prosthesis. An access for oral hygiene (1 $\mathrm{mm}$ space under the frame for cleaning purposes) was made. The framework was constructed using castable resin (Duralay, Reliance Dental MFG Co, Worth, IL, USA) and tried in patient mouth for passive fit, then invested, and casted with cobalt-chromium alloy. The cast metal was tried in patient mouth for passivity. Acrylic artificial teeth were arranged over the framework and waxing up was completed. Intraoral try-in for occlusion and esthetics was completed. The prothesis was processed into heat cure acrylic resin, finished and polished (fig 5). The screws access holes were sealed with composite resin. ${ }^{(11)}$

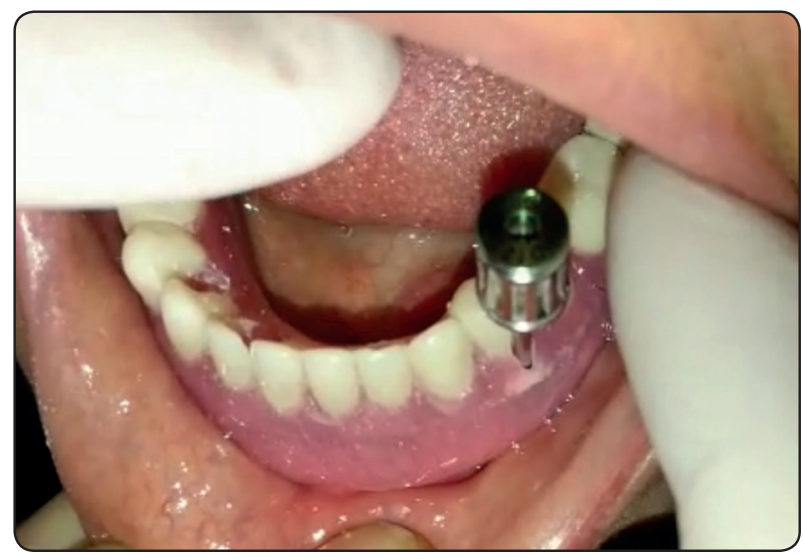

Fig. (5) The final metal acrylic screw retained hybrid prosthesis in place 


\section{Clinical and radiographic evaluations}

The following parameters were recorded for each implant by the same examiner (I.S) at baseline (immediately after loading,T0), 6 (T6) and 12 (T12) months thereafter: Plaque index (PI) according to Mombelli et al. ${ }^{(17)}$ using the following scores: $0=$ absence of plaque, 1 = plaque detected by probe on the gingival margin, 2 = plaque detected by vision, 3 $=$ plenty of soft plaque material. Gingival index (GI) according to Loe and silness ${ }^{(18)}$ using the following scores: $0=$ absence of bleeding, $1=$ isolated spot bleeding, $2=$ line bleeding, $3=$ sever bleeding. Probing depth (PD): The distance between gingival margin and the depth of the pocket measured by periodontal probe was measured as probing depth. PI, GI and PD recorded at mid-mesial, mid-labial, mid-distal and mid lingual aspects of each fixture. The stability of the fixtures (ISQ): was measured by means of resonance frequency analysis (RFA, Osstell ${ }^{\mathrm{TM}}$; Sweden) and expressed with ISQ measurement scale (implant stability quotient) after attaching the implant-specific Smart Pegs to the implant $^{(19,20)}$.

Marginal bone was evaluated using standardized digital panoramic radiographs (Digora Optime, Soredex) because the high degree of ridge resorption precludes the use of periapical films with film holder in the patient mouth. An independent radiologist performed the radiographic readings. To standardize all panoramic images, each participant occluded on an occlusal template attached to the chin stabilizer of the machine. To calculate magnification factor, implant dimensions in the radiographs were compared to actual implant dimension to correct bone height measurements in the radiographs to their actual values. Vertical bone loss was calculated as the distance between implant abutment connection to first bone to implant contact using the accompanying software (Scanora Lite). Measurements were made on the mesial and distal aspect of each implant and the mean was subjected to statistical analysis. The loss of bone was calculated as the difference between visits and baseline values

The implant survival rate was calculated following the survival criteria of Malo ${ }^{(21)}$ : (1) implant provide good support for prosthesis; (2) is stable when individually (3) no signs of infection; (4) no radiolucent areas around the implants; (5) good aesthetic outcome of the rehabilitation;(6) no paresthesia or numbness and (7) patient comfort and good oral hygiene. Survival rate was estimated on implant level

\section{Statistical analysis}

The data were explored for normality of distribution. The data was non-parametric and violated the normal distribution. Descriptive statistics of plaque and gingival scores were presented as median (Med), minimum (mini), and maximum (maxi). On the other hand, the descriptive statistics of pocket depth, implant stability and bone loss were presented as mean (X) and standard deviation (SD). The difference in parameters between time intervals was detected using Friedman test followed by Wilcoxon signed ranks test for pair-wise comparison between observation times. Mann Whitney test was used to compare clinical and radiographic outcomes between anterior and posterior implants. Kaplan Meir analysis was used to calculate implant survival rate. The data were analyzed using SPSS ${ }^{\circledR}$ software version 25 (SPSS Inc., Chicago, IL, USA). P-values $<0.05$ were considered to be significant.

\section{RESULTS}

Comparisons of Plaque and gingival scores between observation times and implant positions (canine and premolar) is presented in table 1. Canine and premolar implants showed significant increase in plaque scores with passage of time. However, no difference in gingival scores with advance of time was observed. Multiple comparisons of each 2-time intervals are shown in the table. There was a 
difference in plaque and bleeding (gingival) scores between each 2 time points. Comparison of these scores between canine and premolar implants is presented in table 1. Premolar implants showed significant higher plaque scores than canine implants at different observation times. However, no difference in gingival scores was noted between canine and premolar implants at different time intervals.

Comparisons of Probing depth, implant stability, and resorption of peri-implant crestal bone between observation times and implant positions (canine and premolar) is presented in table 2. Canine and premolar implants showed significant increase in probing depth and bone loss with passage of time. However, no difference in implant mobility with passage of time was observed. Multiple comparisons of each 2-time intervals are shown in the table. There was a difference in probing depth between each 2 time points. Loss of bone increased markedly from 6 months to 12 months for both implant positions.
Comparison of probing depth and bone loss between canine and premolar implants is shown in table 2. Premolar implants showed significant higher probing depth than canine implants at different observation times. Premolar implants showed significant higher bone loss than canine implants at T6 and T12. However, no difference in implant stability was noted between canine and premolar implants at different time intervals.

Two immediately loaded implants in one patient were failed before 6-month. Other implants (24 $-2=22$ ) passed the 1-year follow-up, resulting in $91.6 \%$ cumulative survival rate. The survival analysis plot using Kaplan Meier is presented in fig 6. The prothesis was converted to 2-implant retained overdentures after relining and attached to canine implants with locator attachment. The failures were associated with pain, mobility and bone loss. Using Log rank test, no significant difference in survival rate between canine and premolar fixtures was noted $(\mathrm{p}=0.15)$.

TABLE (1) Comparison of plaque and gingival scores between time intervals and implant positions

\begin{tabular}{|c|c|c|c|c|}
\hline \multicolumn{2}{|c|}{ Base line } & 6 months & 12 months & $\begin{array}{c}\text { Freidman test } \\
\text { (p value) }\end{array}$ \\
\hline $\begin{array}{c}\text { Plaque indices } \\
\text { Canine implants Median } \\
\text { (Minimum-Maximum) }\end{array}$ & $.00(.00-1.00) \mathrm{a}$ & $.00(.00-.200) \mathrm{b}$ & $1.00(1.00-3.00) \mathrm{c}$ & $.005^{*}$ \\
\hline $\begin{array}{c}\text { Premolar implants Median } \\
\text { (Minimum-Maximum) }\end{array}$ & $.00(.00-1.00) \mathrm{a}$ & $1.00(1.00-.300) \mathrm{b}$ & $2.00(2.00-3.00) \mathrm{c}$ & $.008^{*}$ \\
\hline $\begin{array}{c}\text { Mann Whitney Test } \\
\text { (p value) }\end{array}$ & 1.00 & $.023^{*}$ & $.010^{*}$ & \\
\hline $\begin{array}{c}\text { Gingival indices } \\
\text { Canine implants Median } \\
\text { (Minimum-Maximum) }\end{array}$ & $.00(.00-.00) \mathrm{a}$ & $.00(.00-.00) \mathrm{a}$ & $.00(.00-.00) \mathrm{a}$ & 1.00 \\
\hline $\begin{array}{c}\text { Premolar implants Median } \\
\text { (Minimum-Maximum) }\end{array}$ & $.00(.00-.00) \mathrm{a}$ & $.00(.00-.00) \mathrm{a}$ & $.00(.00-.00) \mathrm{a}$ & 1.00 \\
\hline $\begin{array}{c}\text { Mann Whitney Test } \\
\text { (p value) }\end{array}$ & 1.00 & 1.00 & 1.00 & \\
\hline
\end{tabular}

*significant difference at .05. A similar letters show significant difference 2 time intervals 
TABLE (2) Comparison of probing depth, implant stability and bone loss between time intervals and implant positions

\begin{tabular}{|c|c|c|c|c|}
\hline & Base line & 6 months & 12 months & $\begin{array}{l}\text { Freidman test } \\
\text { (p value) }\end{array}$ \\
\hline \multicolumn{5}{|l|}{ Probing depth } \\
\hline $\begin{array}{c}\text { Canine implants } \\
\text { Mean } \pm \text { standard deviation }\end{array}$ & $1.34 \pm .38 \mathrm{a}$ & $1.41 \pm .64 \mathrm{~b}$ & $1.61 \pm .66 \mathrm{c}$ & $.045^{*}$ \\
\hline $\begin{array}{c}\text { Premolar implants } \\
\text { Mean } \pm \text { standard deviation }\end{array}$ & $1.79 \pm .34 \mathrm{a}$ & $1.82 \pm .77 \mathrm{~b}$ & $1.98 \pm .80 \mathrm{c}$ & $.036^{*}$ \\
\hline $\begin{array}{c}\text { Mann Whitney Test } \\
\text { (p value) }\end{array}$ & $.030^{*}$ & $.035^{*}$ & $.023^{*}$ & \\
\hline \multicolumn{5}{|l|}{ Implant stability } \\
\hline $\begin{array}{c}\text { Canine implants } \\
\text { Mean } \pm \text { standard deviation }\end{array}$ & $66.51 \pm 1.16 \mathrm{a}$ & $66.2 \pm 1.25 \mathrm{a}$ & $67.40 \pm 1.33 \mathrm{a}$ & .231 \\
\hline $\begin{array}{c}\text { Premolar implants } \\
\text { Mean } \pm \text { standard deviation }\end{array}$ & $65.121 \pm 1.78 \mathrm{a}$ & $65.3 \pm 1.46 \mathrm{a}$ & $66.40 \pm 1.47 \mathrm{a}$ & .174 \\
\hline $\begin{array}{c}\text { Mann Whitney Test } \\
\text { (p value) }\end{array}$ & .36 & .25 & .18 & \\
\hline \multicolumn{5}{|l|}{ Bone resorption } \\
\hline $\begin{array}{c}\text { Canine implants } \\
\text { Mean } \pm \text { standard deviation }\end{array}$ & - & $.68 \pm .47 \mathrm{a}$ & $.81 \pm .39 \mathrm{~b}$ & $.021 *$ \\
\hline $\begin{array}{c}\text { Premolar implants } \\
\text { Mean } \pm \text { standard deviation }\end{array}$ & - & $.97 \pm .54 \mathrm{a}$ & $1.10 \pm .57 \mathrm{~b}$ & $.030 *$ \\
\hline $\begin{array}{c}\text { Mann Whitney Test } \\
\text { (p value) }\end{array}$ & & $.002 *$ & $.001 *$ & \\
\hline
\end{tabular}

*significant difference at .05. A similar letters show significant difference 2 time intervals

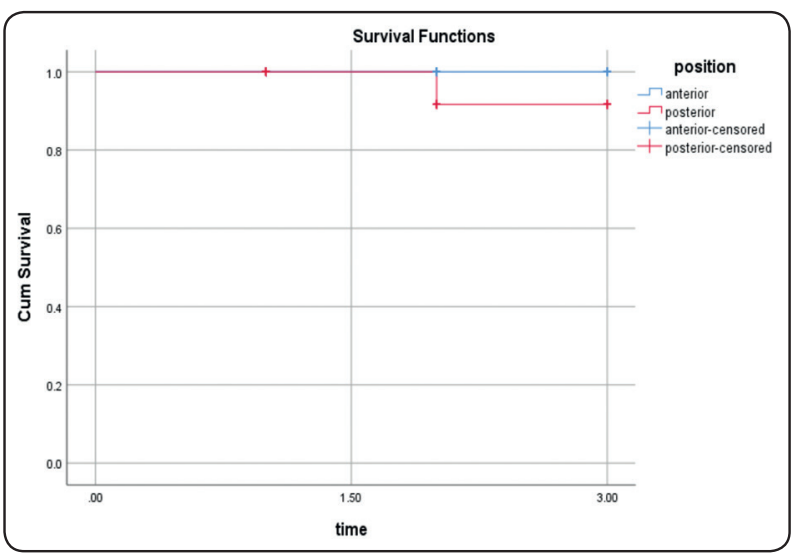

Fig. (6) Kaplan Meier analysis survival rate of anterior and posterior implants

\section{DISCUSSION}

The trans-alveolar placement technique in this study requires a buccal inclination of the implants up to $30^{\circ}$ beside the distal inclination of the All on four implant direction. The distal and buccal inclination of the implants is compensated by $30^{\circ}$ muliunit abutments ${ }^{(11)}$. The lower denture was modified by shortening of the flanges, thus the denture was similar to the provisional fixed acrylic partial denture used in the original protocol of $\mathrm{Malo}^{(4)}$. These modifications in many cases were minimal due to the shallow mandibular sulcus 
caused by increased ridge atrophy. Usually the denture flanges are thick enough to prevent fracture. However, if denture modification makes the denture liable to fracture, the denture was reinforced in the lab by metallic meshwork. In some cases, thinning of the bone at crest of the ridge preclude implant placement at the level of the ridge crest. This was overcomed by submerging the implants 2 or $3 \mathrm{~mm}$ below the crest of the ridge to preserve at least $1 \mathrm{~mm}$ buccal and lingual bone around the implant neck.

The plaque scores increased significantly with time for canine and premolar implants. The increased plaque accumulation may be attributed to the decreased manual indexterity of old participants causing in reduced cleaning. Also relieve spaces made around the metal copings to avoid gingival traumatization may be responsible for increased plaque accumulation. The increased plaque scores for premolar implants compared to canine implants may be due to the difficulty of cleaning the prosthesis due to presence of acrylic flanges and the inaccessibility of posterior implants compared to anterior ones. Similarly, Krennmair et $\mathrm{al}^{(22)}$ found increase plaque scores around tilted posterior implants compared to axial anterior implants and attributed this finding to the impaired cleaning process of posterior implants caused by prosthesis design (due to presence of cantilever) with excessively close gingival attachment. However, the increased plaque accumulation did not cause an increase in gingival inflammation and gingival index over the time. Also, no significant effect of the implant location on gingival scores was noted.

Pocket depth increased significantly with time. Similarly, several authors reported an increase in pocket depth around implants supporting "All on four" prosthesis ${ }^{(22,23)}$. Premolar implants showed increased pocket depth than canine implants. This may be due to increased plaque accumulation and gingival enlargement around posterior implant. Another explanation may be attributed to the surgical technique used for placement of posterior (inclined) implants, which necessitate subcrestal merging of the inclined implants with preparation of occlusal flare in the crestal bone to accommodate the multiunit abutments. This may increase bone loss and creates deeper pockets around posterior implants compared to anterior ones. Another explanation could be due to the high bone resorption of posterior implants compared to anterior implants as confirmed by the results of this study.

The absence of difference in fixture mobility between observation times and between implant positions may be due to all fixtures are installed with high insertion torque with more bone to implant contact after healing period. The lack of difference in implant mobility between anterior (vertical) and posterior (tilted) implants was in line with results of other studies ${ }^{(24-26)}$ and may be due to the high bone quality in the interforaminal area of the mandibular jaw.

The amount marginal bone loss after one year not exceeds $1 \mathrm{~mm}$ for anterior and posterior implants. This rate of bone loss remains within the normal rate that is $1.2 \mathrm{~mm}$ in the first year ${ }^{(27-31)}$. The increased bone loss from 6 months to 12 months could be due to the natural biological bone resorption and formation, which occurs after implant placement and immediate bone response to healing, and reorganization combined with function stresses of immediate loading. The increased bone loss around premolar implants compared to anterior implants may be due to subcrestal merging of the inclined implants with preparation of occlusal flare in the crestal bone to accommodate the multiunit abutments. This technique creates thin bone around the implants especially with narrow width of the ridge rest. This thin bone may be liable to bone loss especially under occlusal load. In contrast, another clinical study on All on four implant prosthesis by lopes et al found no variation in bone resorption between vertically and posteriorly tilted fixtures after 5-year. ${ }^{(32)}$

The acceptable implant survival in the current investigation may be due to trans-alveolar placement which make the fixture more parallels to the lingual 
cortical plate, thus increase length of the fixture ${ }^{(11)}$. Moreover, the opposing arches contained complete dentures which dampen the occlusal forced transmitted to the mandibular denture especially in the critical period of immediate loading. The acrylic resin provides greater dampening effect of occlusal load on the prosthesis ${ }^{(33-35)}$. Furthermore, the increased bone quality in the interforaminal area of the mandibular increases implant stability and contributed to increased implant survival. In cases of decreased bone density which is detected by tactile sensation of the surgeon during drilling, the final drill was omitted to obtain adequate primary stability required for immediate loading ${ }^{(15)}$.

The limitations of the study included the small patient number, the short study period, and the absence of control group. Therefore, long term controlled clinical trials with adequate sample size and control group (which include the conventional placement of posterior implants) are still required.

\section{CONCLUSION}

Within the limits of this investigation, computer guided flapless vestibular to lingual trans-alveolar posterior fixture installation for All on four implant prosthesis in case of severely atrophied mandible is a predictable and reliable method as it was associated with favorable clinical and radiographic peri-implant outcomes after one year. However, the outcome of this technique should be compared to the outcomes of conventional implant placement method for All on four implant concept to ensure it efficacy.

\section{REFERENCE}

1. Weinstein R, Agliardi E, Fabbro MD, Romeo D, Francetti L. Immediate rehabilitation of the extremely atrophic mandible with fixed full-prosthesis supported by four implants. Clin Implant Dent Relat Res. 2012;14(3):434-41.

2. Sadowsky SJ. The implant-supported prosthesis for the edentulous arch: design considerations. J Prosthet Dent. 1997;78(1):28-33.
3. Malo P, Rangert B, Nobre M. "All-on-Four" immediatefunction concept with Branemark System implants for completely edentulous mandibles: a retrospective clinical study. Clin Implant Dent Relat Res. 2003;5 Suppl 1:2-9.

4. Malo P, Rangert B, Nobre M. All-on-4 immediate-function concept with Branemark System implants for completely edentulous maxillae: a 1-year retrospective clinical study. Clin Implant Dent Relat Res. 2005;7 Suppl 1:S88-94.

5. Pozzi A, Sannino G, Barlattani A. Minimally invasive treatment of the atrophic posterior maxilla: a proof-of-concept prospective study with a follow-up of between 36 and 54 months. J Prosthet Dent. 2012;108(5):286-97.

6. Francetti L, Agliardi E, Testori T, Romeo D, Taschieri S, Del Fabbro M. Immediate rehabilitation of the mandible with fixed full prosthesis supported by axial and tilted implants: interim results of a single cohort prospective study. Clin Implant Dent Relat Res. 2008;10(4):255-63.

7. Krekmanov L. Placement of posterior mandibular and maxillary implants in patients with severe bone deficiency: a clinical report of procedure. Int J Oral Maxillofac Implants. 2000;15(5):722-30.

8. Cawood JI, Howell RA. A classification of the edentulous jaws. Int J Oral Maxillofac Surg. 1988;17(4):232-6.

9. Jensen OT, Adams MW. All-on-4 treatment of highly atrophic mandible with mandibular V-4: report of 2 cases. J Oral Maxillofac Surg. 2009;67(7):1503-9.

10. Jensen OT, Adams MW, Cottam JR, Parel SM, Phillips WR. The all on 4 shelf: mandible. J Oral Maxillofac Surg. 2011;69(1):175-81.

11. Jensen O, Cottam J, Adams M, Adams S. Buccal to lingual transalveolar implant placement for all on four immediate function in posterior mandible: report of 10 cases. J Oral Maxillofac Surg. 2011;69(7):1919-22.

12. Malo P, de Araujo Nobre M, Lopes A. The use of computer-guided flapless implant surgery and four implants placed in immediate function to support a fixed denture: preliminary results after a mean follow-up period of thirteen months. J Prosthet Dent. 2007;97(6 Suppl):S26-34.

13. Patzelt SB, Bahat O, Reynolds MA, Strub JR. The all-onfour treatment concept: a systematic review. Clin Implant Dent Relat Res. 2014;16(6):836-55.

14. Malo Bo R, Nobre M. Concept with Brlaanemark System Itextregistered Implants for Completely Edentulous Mandibles: A Retrospective Clinical Study. Implant dentistry. 2003:2-9. 
15. Sannino G, Bollero P, Barlattani A, Gherlone E. A Retrospective 2-Year Clinical Study of Immediate Prosthetic Rehabilitation of Edentulous Jaws with Four Implants and Prefabricated Bars. J Prosthodont. 2017;26(5):387-94.

16. Galindo DF, Butura CC. Immediately loaded mandibular fixed implant prostheses using the all-on-four protocol: a report of 183 consecutively treated patients with 1 year of function in definitive prostheses. The International journal of oral \& maxillofacial implants. 2012;27(3):628-33.

17. Mombelli A, van Oosten MA, Schurch E, Jr., Land NP. The microbiota associated with successful or failing osseointegrated titanium implants. Oral Microbiol Immunol. 1987; 2(4):145-51.

18. Loe H, Silness J. Periodontal Disease in Pregnancy. I. Prevalence and Severity. Acta Odontol Scand. 1963;21:533-51.

19. Meredith N, Alleyne D, Cawley P. Quantitative determination of the stability of the implant-tissue interface using resonance frequency analysis. Clin Oral Implants Res. 1996;7(3):261-7.

20. Glauser R, Sennerby L, Meredith N, Ree A, Lundgren A, Gottlow J, et al. Resonance frequency analysis of implants subjected to immediate or early functional occlusal loading. Successful vs. failing implants. Clin Oral Implants Res. 2004;15(4):428-34.

21. Malo P, de Araujo Nobre M, Lopes A, Francischone C, Rigolizzo M. "All-on-4” immediate-function concept for completely edentulous maxillae: a clinical report on the medium (3 years) and long-term (5 years) outcomes. Clin Implant Dent Relat Res. 2012;14 Suppl 1:e139-50.

22. Krennmair S, Weinländer M, Malek M, Forstner T, Krennmair G, Stimmelmayr M. Mandibular Full-Arch Fixed Prostheses Supported on 4 Implants with Either Axial Or Tilted Distal Implants: A 3-Year Prospective Study. Clin Implant Dent Relat Res. 2016;18(6):1119-33.

23. Ayna M, Gulses A, Acil Y. A comparative study on 7-year results of "All-on-Four" immediate-function concept for completely edentulous mandibles: metal-ceramic vs. barretained superstructures. Odontology. 2018;106(1):73-82.

24. Balshi SF, Allen FD, Wolfinger GJ, Balshi TJ. A resonance frequency analysis assessment of maxillary and mandibular immediately loaded implants. The International journal of oral \& maxillofacial implants. 2005;20(4):584-94.
25. Balshi TJ, Wolfinger GJ, Slauch RW, Balshi SF. A retrospective analysis of 800 Branemark System implants following the All-on-Four protocol. Journal of prosthodontics: official journal of the American College of Prosthodontists. 2014;23(2):83-8.

26. Ayub KV, Ayub EA, Lins do Valle A, Bonfante G, Pegoraro T, Fernando L. Seven-Year Follow-up of Full-Arch Prostheses Supported by Four Implants: A Prospective Study. The International journal of oral \& maxillofacial implants. 2017;32(6):1351-8.

27. Albrektsson T, Zarb G, Worthington P, Eriksson AR. The long-term efficacy of currently used dental implants: a review and proposed criteria of success. Int J Oral Maxillofac Implants. 1986;1(1):11-25.

28. Albrektsson T, Zarb GA. Current interpretations of the osseointegrated response: clinical significance. Int J Prosthodont. 1993;6(2):95-105.

29. Zarb GA, Albrektsson T. Consensus report: towards optimized treatment outcomes for dental implants. J Prosthet Dent. 1998;80(6):641.

30. van Steenberghe D, Quirynen M, Naert I, Maffei G, Jacobs R. Marginal bone loss around implants retaining hinging mandibular overdentures, at 4-, 8- and 12-years follow-up. J Clin Periodontol. 2001;28(7):628-33.

31. Chung DM, Oh TJ, Lee J, Misch CE, Wang HL. Factors affecting late implant bone loss: a retrospective analysis. Int J Oral Maxillofac Implants. 2007;22(1):117-26.

32. Lopes A, Maló P, Nobre MA, Fernández MMS. The NobelGuide ${ }^{\circledR}$ All-on-4® Treatment Concept for Rehabilitation of Edentulous Jaws: A Prospective Report on Medium- and Long-Term Outcomes.Clinical Implant Dentistry and Related Reasesrch 2015; 17(S2):343-764.

33. Ciftci Y, Canay S. The effect of veneering materials on stress distribution in implant-supported fixed prosthetic restorations. Int J Oral Maxillofac Implants. 2000;15(4):571-82.

34. Davis DM, Rimrott R, Zarb GA. Studies on frameworks for osseointegrated prostheses: Part 2. The effect of adding acrylic resin or porcelain to form the occlusal superstructure. Int J Oral Maxillofac Implants. 1988;3(4):275-80.

35. Gracis SE, Nicholls JI, Chalupnik JD, Yuodelis RA. Shock-absorbing behavior of five restorative materials used on implants. Int J Prosthodont. 1991;4(3):282-91. 